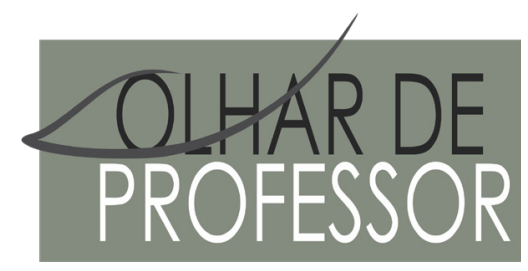

DOI: 10.5212/OLHARPROFR.v.23.2020.15193.209209226782.0525

\title{
EXAME NACIONAL DO ENSINO MÉDIO, POLÍTICA EDUCACIONAL E PROPOSTA DE FORMAÇÃO PARA 0 DESENVOLVIMENTO DE HABILIDADES E COMPETÊNCIAS
}

\author{
SECONDARY EDUCATION NATIONAL EXAMINATION (ENEM], EDUCATIONAL POLICY AND FORMATION \\ PROPOSAL FOR THE DEVELOPMENT OF SKILLS AND COMPETENCES \\ EXAMEN NACIONAL DE ENSEÑANZA SECUNDARIA, POLÍTICAS EDUCATIVAS Y PROPUESTAS DE \\ FORMACIÓN PARA EL DESARROLLO DE HABILIDADES Y COMPETENCIAS
}

\author{
RUBIANA BRASILIO SANTA BÁRBARA* \\ MARIA TEREZINHA BELLANDA GALUCH ${ }^{\text {** }}$ \\ VINÍCIUS ADRIANO DE FREITAS ${ }^{\text {*** }}$
}

\begin{abstract}
Resumo: Objetiva-se compreender a relação entre o Exame Nacional do Ensino Médio (Enem) e os princípios educacionais mobilizados na esfera política, mediante a análise das competências e habilidades exigidas na avaliação fundamentando-se na Teoria Crítica da Sociedade. Os resultados e as discussões da análise deixam perceber que o Enem, como expressão da política educacional brasileira, corrobora uma concepção formativa em que o desenvolvimento de competências e habilidades cumpre a função de formar sujeitos adaptados aos anseios e aos valores da sociedade vigente, cujo desenvolvimento do humano não é prioridade, portanto, participa da crise da formação.
\end{abstract}

Palavras-Chave: Teoria Crítica da Sociedade; Enem; Política Educacional.

\begin{abstract}
The objective is to understand the relationship between the Enem and the educational principles mobilized in the political sphere, through the analysis of the competences and skills required in the evaluation, based on the Critical Theory of Society. The results and discussions of the analysis show that the Enem as an expression of the Brazilian educational policy, corroborates a formative conception in which the development of competences and skills fulfills the function of forming subjects adapted to the longings and the values of the current society, of which human development is not a priority, therefore, it participates in the crisis of formation.
\end{abstract}

Keywords: Critical Theory of Society; Enem; Educational Policy.

Resumen: El objetivo es entender la relación entre el examen nacional de enseñanza secundaria y los principios educativos movilizados en la esfera política, a través del análisis de competencias y habilidades requeridas en la evaluación, fundamentándose en la Teoría Critica de la Sociedad. Los resultados y el análisis realizado permiten percibir que el Examen Nacional de Enseñanza Secundaria como expresión de la política educativa brasileña, corrobora una concepción formativa en la que el desarrollo de competencias y habilidades cumple la función de

\footnotetext{
* Doutora em Educação pela Universidade Estadual de Maringá (UEM). Professora do Departamento de Métodos e Técnicas da UEM e professora do Plano Nacional de Formação de Professores (PARFOR) na mesma instituição. E-mail: rubibras@ hotmail.com

** Doutora em Educação pela PUCSP. Professora Associada na Universidade Estadual de Maringá (UEM). E-mail: mtbgaluch@ uem.br

${ }^{* * *}$ Mestre e Doutorando em Educação pela Universidade Estadual de Maringá (UEM). Docente da rede municipal de ensino de Cianorte/PR e Professor Assistente no Curso de Pedagogia da UEM. E-mail: vafreitas2@uem.br
} 
formar sujetos adaptados a los anhelos y a los valores de la sociedad vigente, cuyo desarrollo del humano no es prioridad, por lo tanto, participa de la crisis formativa.

Palabras claves: Teoría Critica de la Sociedad; Examen Nacional de Enseñanza Secundaria; Política Educativa.

\section{INTRODUÇ̃̃O}

O Exame Nacional do Ensino Médio (Enem) é uma das avaliações de larga escala que participa do movimento das reformas educacionais, ao mesmo tempo que é influenciada por elas. Trata-se de uma avaliação que se fortalece como fruto de reformas e de políticas públicas implementadas a partir da década de 1990.

Apresenta-se como um dos instrumentos que difundem a formação voltada para o desenvolvimento das competências e habilidades ${ }^{1}$, já que é essa a perspectiva assumida ao avaliar o estudante ao término do ensino médio ou posteriormente.

O Enem respalda os organismos internacionais para identificarem se, e em que medida, o país beneficiado por empréstimos está atendendo aos objetivos impostos por eles e, portanto, uma forma de controle da formação oferecida na educação básica. Nesse sentido, é uma avaliação padronizada e vinculada a políticas de responsabilização².

Com a ideia e com o compromisso traçados por instâncias superiores - Organização das Nações Unidas (ONU), Organização das Nações Unidas para a Educação, a Ciência e a Cultura (Unesco), Fundo das Nações Unidas para a Infância (Unicef), Fundo Monetário Internacional (FMI), Banco Mundial (BM), etc. -, a educação escolar e os aspectos que a envolvem, inclusive as avaliações em larga escala, direcionam a formação.

Isto posto, temos por objetivo compreender a relação entre o Exame Nacional do Ensino Médio (Enem) e os princípios educacionais mobilizados na esfera política, mediante a análise das competências e habilidades exigidas nessa avaliação de larga escala.

O estudo caracteriza-se como documental-bibliográfico, tendo como fontes documentos nacionais, produzidos pelo Instituto Nacional de Estudos e Pesquisas Anísio Teixeira (INEP) sobre o Enem (BRASIL, 1998, 2000, 2001, 2002, 2005), e internacionais como os produzidos pelo Banco Mundial (BM), pela Organização para a Cooperação e Desenvolvimento Econômico (OCDE) e dados indicadores tais como o World Indicators of Skills for Employment (WISE), Better life index, Better policies for better lives, Getting Skills Right, Stat e Education.

Mediante elementos destacados dos documentos e amparados pela Teoria Crítica da Sociedade, analisamos aspectos avaliados pelo Enem, de modo a nos aproximarmos do perfil da formação do estudante do ensino médio esperado pelo Exame e de relacionar a avaliação com os princípios educacionais mobilizados na esfera política.

Os estudos dos documentos sobre o Enem trazem informações que coadunam com os documentos e indicadores internacionais em relação às funções do Exame como a flexibilização de acesso ao ensino superior, haja vista que, aos poucos, ele tem tomado o lugar dos vestibulares tradicionais, tornando-se mercadoria em um universo de cursinhos preparatórios.

Nesse contexto, ao mesmo tempo em que avalia o conhecimento que o estudante adquiriu durante o ensino médio, delineia o perfil do estudante ao fim dessa etapa da educação básica. Portanto o ensino

\footnotetext{
${ }^{1}$ Quanto aos conceitos de ‘competência’ e de 'habilidade’, Cafiero (2005, p. 45) diz: (i) competência significa saber utilizar um 'conjunto de habilidades' em função de um determinado objetivo, para resolver um dado problema; (ii) habilidade significa saber 'fazer'. Perrenoud (2000, p. 15, grifo do autor), ao se referir às competências, afirma: "uma capacidade de mobilizar diversos recursos cognitivos para enfrentar um tipo de situação”.

2Sobre o conceito de 'políticas de responsabilização', citamos o artigo de Nigel Brooke intitulado O futuro das políticas de responsabilização educacional no Brasil. Nele, dentre outras questões, o autor explica que a “[...] exigência por maiores informações sobre os resultados dos sistemas escolares tem sido respondida pela implementação de políticas de accountability, ou seja, de responsabilização, mediante as quais se tornam públicas as informações sobre o trabalho das escolas e consideram-se os gestores e outros membros da equipe escolar como co-responsáveis pelo nível de desempenho alcançado pela instituição" (BROOKE, 2006, p. 378).
} 
médio acaba sendo um orientador para a organização de um ensino voltado para treinar o perfil que o Exame requer, sendo o inverso também verdadeiro.

Um olhar dialético revela o seguinte cenário: por um lado, o Exame se apresenta como possibilidade de educação para o indivíduo; por outro lado, acaba promovendo uma divisão entre aqueles que podem seguir com seus estudos e aqueles que seguirão para os cursos técnicos, ou ainda, que devem 'aprender a empreender' em uma sociedade que não dispõe de espaço para todos. Nesse sentido, prevalecem as formas de adaptação que possam conduzir o indivíduo a desenvolver comportamentos guiados por competências e habilidades.

Conforme explica Forrester (1997), no contexto atual, o indivíduo idealizado pela OCDE é aquele que, ao perder seu emprego, deve ser capaz de inserir-se no mercado rapidamente. Um indivíduo que esteja apto para desenvolver qualquer função, visto que o emprego é algo em extinção.

Para isso, há que se ter certa qualificação, ou melhor, certos comportamentos desejáveis para que não seja sucumbido à própria miséria e se torne uma ameaça para a coesão social; um indivíduo que acompanhe as mudanças e que deve estar aberto às transformações no processo de trabalho. O gadget ${ }^{3}$ que bem representa a flexibilidade e a instabilidade da sociedade é a empregabilidade, ou seja, é ela a promessa de um "belo futuro" (FORRESTER, 1997, p. 119).

Este artigo está organizado em dois itens, sendo que no primeiro buscamos, por meio de documentos nacionais e internacionais, compreender os princípios educacionais que fundamentam o Enem, considerando esse exame uma expressão da política educacional.

O foco no Enem nos leva a conhecer suas características, bem como as orientações que norteiam a proposta de formação voltada para as competências e para a eficiência. No segundo item, apresentamos os resultados das análises e explicitamos a possibilidade de a Teoria Crítica da Sociedade permitir a reflexão crítica sobre os limites da formação cobrada pelo Enem e requerida no contexto atual, revelando as contradições dessa formação quando analisada da perspectiva do humano.

\section{DESDOBRAMENTOS DA POLÍTICA EDUCACIONAL PARA A FORMAÇÃO DOS SUJEITOS}

A reforma do Estado nos anos de 1990 trouxe diversos programas para assegurar o acesso e a permanência na escola, como plano de financiamento, de gestão e também formas de intervenção avaliativa, "[...] como é o caso da implantação do Censo Escolar, do Sistema de Avaliação da Educação Básica (SAEB), do Exame Nacional do Ensino Médio (ENEM) e do Exame Nacional de Cursos (Provão)" (SHIROMA; MORAES; EVANGELISTA, 2011, p. 74). É nesse cenário das avaliações para o controle de desempenho que o Enem foi criado.

Pela importância dada às avaliações nacionais há que se questionar: de fato, estas avaliações contribuíram para o bom funcionamento do sistema educacional e para uma formação humana, haja vista que promovem a competição para conseguir um "lugar no ranking”? (SHIROMA; MORAES; EVANGELISTA, 2011, p. 98).

Além dos resultados entre as instituições evidenciarem aquelas mais bem sucedidas e que se tornam excelências, promovem uma disputa por vagas tanto por estudantes como por professores mais competentes. Na afirmação de Shiroma, Moraes e Evangelista (2011, p. 99): “[...] o processo de seleção dos melhores é sutil, a marginalização é dissimulada, um verdadeiro - 'apartheid educacional' [...]”.

A educação se torna um negócio. A preparação para enfrentar as avaliações em larga escala, com cursos destinados especificamente para tal fim, significa um mercado promissor que, aliado à “[...] situação de instabilidade, incerteza, vulnerabilidade a que estão expostos com o aumento do desemprego impulsiona o mercado de venda de consultorias, de diplomas, de promessas de empregabilidade" (SHIROMA; MORAES; EVANGELISTA, 2011, p. 100).

\footnotetext{
${ }^{3}$ Instrumento, invenção.
} 
O documento básico e oficial do Enem dos anos de 2000, 2001 e 2002 descreve o Exame a partir de 1998, ressaltando que foi criado pelo Inep como um instrumento de política pública, sendo valioso para subsidiar e para a adequação às políticas de educação no país.

Logo no início, os três documentos básicos (BRASIL, 2000, 2001, 2002) destacam o objetivo principal do Exame: avaliar o conhecimento do aluno ao fim do ensino médio e analisar o desenvolvimento de competências fundamentais para o exercício pleno da cidadania.

Ressaltam que "as tendências internacionais" tratam da importância de uma formação geral na educação básica não só para a continuação dos estudos, mas para a aplicação e a inserção no mercado de trabalho cada vez mais competitivo. Explicitam também que o Exame tem por objetivo uma formação capaz de desenvolver habilidades para enfrentar situações-problema e o mundo em constantes mudanças (BRASIL, 2002, p. 5).

A avaliação é elaborada mediante uma matriz que indica as competências e habilidades que estão vinculadas aos conteúdos do ensino fundamental e médio e que são adequadas ao aluno concluinte do ensino médio, o que vai ao encontro dos documentos como os do Banco Mundial (BM), e exposições em sites oficiais dos princípios da Organização de Cooperação e de Desenvolvimento Econômico (OCDE) ${ }^{4}$ e da Organização das Nações Unidas para a Educação, a Ciência e a Cultura (UNESCO).

A exemplo, o Relatório do BM (2000, s/p, tradução nossa) Brazil - secondary Education in Brazil: time to move forward ${ }^{5}$ expressa a necessidade de "[...] uma preparação acadêmica geral, porém mais orientada para as habilidades de vida, no nível secundário, abolindo o tradicional sistema de duas vias de ensino secundário 'geral' e 'vocacional'. Para o BM, o ensino médio no Brasil deve voltar-se para o acadêmico geral, fornecendo uma base educacional para todos os tipos de emprego e permitir um currículo 25\% não acadêmico e no conceito de 'habilidades gerais'.

Mas, quais seriam essas 'habilidades gerais'? São os códigos da modernidade, de acordo com Shiroma, Moraes e Evangelista (2011). São atitudes e comportamentos que tornam as pessoas empregáveis e responsáveis pela sua pobreza ou sucesso. Os documentos que norteiam as reformas curriculares nacionais trazem a ideia de competências e habilidades que capacitem essas pessoas na resolução de problemas. Conforme o documento diz sobre o Enem (BRASIL, 2002, p. 5),

Esta rapidez com que as mudanças sociais se processam e alteram nossa vida cotidiana impõe um padrão mais elevado para a escolaridade básica, e o projeto pedagógico da escola deve objetivar o desenvolvimento de competências com as quais os alunos possam assimilar informações e utilizá-las em contextos adequados, interpretando códigos e linguagens e servindo-se dos conhecimentos adquiridos para a tomada de decisões autônomas e socialmente relevantes. Estas premissas já estão delineadas na atual Lei de Diretrizes e Bases da Educação Nacional (LDB), que introduz profundas transformações no ensino médio, desvinculando-o do vestibular, ao flexibilizar os mecanismos de acesso ao ensino superior, e, principalmente, delineando o perfil de saída do aluno da escolaridade básica [...].

Não é por acaso a relação do Brasil com organizações internacionais, como a OECD (s/d.a) ${ }^{6}$ que, para a área da educação, aponta a necessidade de tornar o indivíduo capaz de lidar com uma sociedade hiperconectada e uma economia baseada no conhecimento. Para a OECD (s/d.a), é importante que os indivíduos aprendam as habilidades capazes de atender às demandas da sociedade - tanto ser empregados, como empregadores.

No que podemos avaliar, se trata de uma medida a ser tomada porque não há trabalho para todos. Atender ao capital significa ter à sua disposição muitos aptos (com diploma) para que se possa pagar o mínimo tendo em vista a livre concorrência.

\footnotetext{
${ }^{4}$ Utilizamos durante o texto a sigla (OECD) que se refere à Organization for economic co-operation and development.

${ }^{5}$ Educação secundária no Brasil: hora de avançar.

${ }^{6}$ No site Better life índex há estatísticas e comparações entre países que possam servir de base para a elaboração de formas eficazes de desenvolvimento em áreas como moradia, renda, emprego, comunidade, escolaridade, meio ambiente, engajamento cívico, saúde, satisfação pessoal, segurança e equilíbrio vida-trabalho.
} 
Contudo, aos jovens 'menos ajustados', deve ser oferecida uma segunda oportunidade, aquela relacionada à aprendizagem informal, para que possam adquirir competências para o mercado de trabalho já que muitos saem da escola antes mesmo de completarem o ensino médio (BM, 2011). Nesse ínterim, a OECD, como uma das maiores orientadoras de avaliações externas e de reformas curriculares, conduz a formação para as competências e não aos conteúdos, direcionando a formação escolar para "uma educação de massa” (ROPÉ; TANGUY, 1997, p. 58).

Eis, aqui, exemplos da formação reduzida a propostas apresentadas por documentos internacionais que definem claramente uma educação para orientar a formação para o trabalho, mas também para o agir no mundo do não trabalho, ajustar-se e se adaptar ao mercado interno e ao externo, ou seja, ao mundo pós-moderno, da liquidez sobre a qual fala Bauman (2001), da incerteza e do desemprego.

Em consonância com as "potências econômicas privadas", o BM, a OECD, o FMI, entre outras, têm poder sobre a economia e a vida política dos países (FORRESTER, 1997, p. 92). Uma das formas de ter controle sobre a economia e a vida política é por meio da educação e, então, a avaliação em larga escala funciona como instrumento a serviço desse controle que possibilita moldar o indivíduo à sociedade vigente.

As avaliações são estabelecidas para identificar, medir e comparar a eficácia dos sistemas de ensino nos diversos países, a exemplo também da OECD que impulsiona políticas em matéria de avaliação dirigida. A avaliação é considerada formativa, porque faz parte do processo de aprendizagem e, por isso, condiciona a reforma de programas (ROPÉ; TANGUY, 1997).

Na página oficial da Organization for economic co-operation and development - OECD (s/d.d, tradução nossa), encontramos na área da educação o subtítulo: "O trabalho da OCDE na educação ajuda indivíduos e nações a identificar e desenvolver o conhecimento e as habilidades que impulsionam melhores empregos e melhores vidas, geram prosperidade e promovem a inclusão social".

Ou seja, a OECD parte do princípio de que é necessário um conjunto de habilidades para viver em uma sociedade hiperconectada e participar da economia cada vez mais baseada em conhecimento. Resta, então, entendermos que conhecimentos são estes. Por isso, a OECD (s/d.b) tem a função principal de medir as habilidades em populações estudantis e desenvolver estratégias de habilidades adaptadas à necessidade e contextos específicos. Assim, ressalta, além das habilidades cognitivas, como a alfabetização e a matemática, as habilidades de comunicar, de influenciar e de negociar.

Entendemos que a alfabetização e a matemática estejam subjugadas aos comportamentos de influenciar e de negociar, em um contexto em que a alfabetização diz mais sobre o letramento e ao negócio, algo relativo ao viver por si.

Competências - Hoje contamos com tecnologias de informação e comunicação e dispositivos que nem sequer haviam sido imaginados há 30 anos. O conjunto de habilidades de que precisamos para participar plenamente e beneficiar-se de nossas sociedades hiperconectadas e economias cada vez mais baseadas em conhecimento também mudou profundamente (OECD, s/d.b, tradução nossa).

A relação entre as habilidades e o mercado de trabalho é objeto de pesquisa e de análise de políticas por parte da OECD (s/d.d), portanto é oportuno enxergar o Enem como resposta política à mudança da necessidade de habilidades, pois responde a um projeto social baseado nas inovações tecnológicas, na empregabilidade e na coesão social, não na formação do humano.

As habilidades e as competências avaliadas pela OECD têm, em suas bases, o chamado Indicadores Mundiais de Competências para Emprego (WISE), que são dados internacionais sobre indicadores de emprego e sobre competências (OECD, s/d.c). Estabelecida pela OECD em estreita colaboração com o BM, o Exchange-traded fund (ETF) - fundo de desenvolvimento, a Organização Internacional do Trabalho (OIT) e a Unesco, a base de dados WISE pode ser usada para criar uma estatística instantânea do status atual do desenvolvimento de habilidades em mais de 200 países.

Essa base de dados - que inclui cerca de 60 indicadores comparáveis internacionalmente para o período de 1990 a 2014 - traz informações referentes às áreas da educação e formação, bem como do emprego e desenvolvimento econômico e social. Além disso, engloba as economias desenvolvidas e as 
em desenvolvimento, o que permite que cada uma avalie os seus desafios em relação às competências e ao desempenho a partir de uma perspectiva comparativa.

A tabela do ano de 2015 da WISE (OECD, 2015)굴 por exemplo, apresenta a) o conteúdo básico de competências: compreensão de leitura; escuta ativa; escrita; fala; habilidades matemáticas e ciências; b) os processos básicos de habilidades: pensamento crítico; aprendizado ativo; estratégias de aprendizado; monitoramento; c) as habilidades sociais: percepção social; coordenação; persuasão; negociação; instrução e orientação de serviço; d) as habilidades complexas de resolução de problemas: habilidades técnicas, como análise de operações e solução de problemas; e) as habilidades de sistemas: julgamento e tomada de decisão; f) as habilidades de gerenciamento de recursos: como o tempo e a gestão de pessoas.

A referida tabela nos ajuda a entender que são apresentadas etapas que devem ser concluídas para se chegar a habilidades de persuasão, de negociação, de resolução de problemas, entre outras ações eficientes. Por isso, compreendemos que a leitura, a escrita e a matemática prestam-se a esses fins e estão subjugadas a eles.

Além de comparativos fornecidos pela WISE sobre competências e habilidades em relação aos indicadores de emprego, a OECD (s/d.a) desenvolveu uma ferramenta interativa denominada Better life índex ${ }^{8}$ - Índice para uma vida melhor - a fim de comparar os países quanto à escolaridade, à moradia, ao trabalho etc., totalizando 11 quesitos considerados necessários para se ter uma vida melhor entre os países membros e também os emergentes denominados parceiros-chave, como é o caso do Brasil (OECD, s/d.a).

A análise destaca que as qualificações exigidas pelo mercado de trabalho são baseadas em conhecimento, o que torna o ensino médio um requisito mínimo para se obter um emprego. Segundo essa ferramenta, “[...] as taxas de conclusão do ensino médio fornecem uma boa indicação sobre o fato de o país estar preparando ou não seus alunos para que atendam às exigências mínimas do mercado de trabalho [...]” (OECD, s/d.a, n.p., tradução nossa) ${ }^{9}$.

No entanto, a conclusão dessa etapa, como ressalta a comparação, não significa êxito na qualidade e no desenvolvimento de capacidades como a leitura, a matemática e a ciência.

Observamos que, seja no comparativo de indicadores de emprego WISE, seja no comparativo para uma vida melhor, Better life índex, da OECD, o desenvolvimento das habilidades e das competências é importante para a produtividade. São elas os pilares que sustentam a entrada dos jovens no mercado de trabalho (ou no mercado sem trabalho) e ainda reforçam a possibilidade de terem acesso a empregos de boa qualidade e de iniciarem carreiras de sucesso ${ }^{10}$.

É expressiva a forma como é priorizado o desenvolvimento de habilidades e de competências como estratégia para impulsionar a economia ${ }^{11}$ que é atrelada à transformação de vidas. É necessário, pois, identificar estratégias para acertar as habilidades em relação às exigências da sociedade, principalmente devido às rápidas mudanças na tecnologia e na globalização.

\footnotetext{
${ }^{7} \mathrm{O}$ banco de dados pode ser acessado pelo OECD.Stat, a plataforma estatística online da OCDE. O banco de dados WISE pode ser encontrado no tema 'Trabalho'. Dois layouts estão disponíveis: $1 .^{\circ}$ ) acessar as tabelas comparativas que permitem a comparação direta de indicadores selecionados ao longo do tempo e entre países; $2 .^{\circ}$ ) acessar as tabelas exibindo perfis de países individualmente, usando todos os indicadores de habilidades disponíveis (OECD, 2015, tradução nossa).

${ }^{8}$ OECD. Better life index. s.d.a. Disponível em: http://www.oecdbetterlifeindex.org/countries/brazil/. Acesso em: 27 fev. 2020.

${ }^{9}$ High-school graduation rates therefore provide a good indication of whether a country is preparing its students to meet the minimum requirements of the job market. OECD. Organization for economic co-operation and development. Better life index. s/d.a. Disponível em: http://www.oecdbetterlifeindex.org/countries/brazil/. Acesso em: 27 fev. 2020.

${ }^{10}$ As habilidades e as competências se tornam cruciais “[...] para que os adultos acompanhem os desenvolvimentos tecnológicos e mantenham a sua empregabilidade em um mundo em rápida mudança e interdependente [...]” (OECD, s/d.a, n.p., tradução nossa).

${ }^{11}$ Como a Estratégia de Competências da OCDE demonstrou, as habilidades transformam vidas e impulsionam economias. Isso, porém, requer que sejam desenvolvidas as habilidades as quais respondem às necessidades do mercado de trabalho e precisam ser totalmente utilizadas por empregados e por empregadores. Nesse sentido, a OCDE pode ajudar os países com três grandes ações: (1) estabelecer boas práticas na avaliação das necessidades de habilidades existentes e emergentes; (2) ajudar os países a fortalecerem a capacidade de resposta de suas políticas de emprego, de educação e de migração a mudanças nas necessidades de habilidades; (3) identificar estratégias eficazes para os países lidarem com o descompasso entre as habilidades dos trabalhadores e as exigências do mercado de trabalho (OECD, s/d.a, n.p., tradução nossa).
} 
No documento Getting Skills Right: Assessing and responding to changing skill needs, a OECD explica as competências voltadas ao emprego, apresentando as necessárias e aquelas já obsoletas, assim como as políticas praticadas para lidar com os desequilíbrios (OECD, s/d.e).

Para a OECD (s/d.e), é necessário saber as competências que precisam ser desenvolvidas, quais são as que correspondem ao mercado de trabalho, para que as políticas de habilidades sejam projetadas com base em informações confiáveis; por isso, o sistema de avaliação e de antecipação, segundo a OECD, traz resultados satisfatórios para a economia e para a sociedade ${ }^{12}$.

Entendemos que não é sem razão que o relatório Educação: um tesouro a descobrir (DELORS, 1996) - o qual se tornou conhecido no Brasil em 1996 - apresenta propostas que se coadunam com os princípios da OECD, principalmente no que tange à avaliação de desempenho e às capacidades a serem desenvolvidas a fim de atender à sociedade em constante mudança, com situações inesperadas e com problemas de desemprego.

O relatório destaca a necessidade de adaptar a educação básica aos contextos particulares de países e de populações pobres, partindo da vida cotidiana para oportunizar a compreensão dos fenômenos naturais e dar acesso a diferentes formas de sociabilidade. Ao se preocupar com uma formação cuja base é o savoir-faire, o relatório deixa claro que as políticas educacionais precisam ser pensadas antes de os jovens e os adolescentes entrarem na vida profissional ou no ensino superior (DELORS, 1996, p. 31).

Em Marcuse (1999, p. 89), encontramos elementos para a reflexão sobre o desempenho e as capacidades, já que o autor fala sobre o desempenho eficiente ligado ao cumprimento de uma tarefa, explicando-a como um "tipo de trabalho" que requer determinadas ações desenvolvidas por aqueles que a criam; assim, promovem-se treinamentos que levam o indivíduo a agir para atingir determinados fins.

A familiarização com as situações cotidianas uniformiza ações eficientes que deixam à mercê a individualidade; dessa forma, a racionalidade está para a execução daquilo que é determinado.

Para exemplificar a racionalidade destacada em Marcuse (1999) temos que, de acordo com o Ministério da Educação (MEC), o Enem é um exame que se difere de outros já realizados, centrando-se no desempenho por competências e vinculando-se a um 'conceito mais abrangente e estrutural da inteligência humana' e também uma prova que exige do participante o conhecimento com a vida cotidiana e imediata.

Nesse sentido, uma única prova abrange todas as áreas de conhecimento. Mas, qual seria esse “conceito mais abrangente e estrutural da inteligência humana”? (BRASIL, 2002, p. 6). O que significa abordar todas as áreas de conhecimento em uma avaliação? Se as bases da avaliação são o conhecimento e a capacidade de mobilizá-los para a resolução de problemas, conforme tratado no documento básico, então a definição de "conceito mais abrangente e estrutural da inteligência humana" está determinado. Conforme destaca o trecho a seguir do documento (BRASIL, 2002, p. 13):

O Enem busca verificar como o conhecimento assim construído pode ser efetivado pelo participante por meio da demonstração de sua autonomia de julgamento e de ação, de atitudes, valores e procedimentos diante de situações-problema que se aproximem, o máximo possível, das condições reais de convívio social e de trabalho individual e coletivo.

Portanto, o conhecimento está subjugado, está em segundo plano. São princípios que respondem à ideologia das competências. Chauí (1983) explica que a ideologia da competência divide aqueles que serão executivos dos que serão executantes, por isso despolitiza a educação, as decisões giram em torno da natureza técnica e promove o domínio de uns sobre os outros.

Mas, como é possível identificar esses princípios na avaliação? Esses princípios se desenvolvem como proposta teórico-metodológica em que se evidenciam competências e habilidades que por sua vez são considerados "conceito mais abrangente e estrutural da inteligência humana” (BRASIL, 2002, p. 6). É o que veremos a seguir.

${ }^{12}$ OECD. Getting Skills Right: Assessing and responding to changing skill needs. s/d.e. Disponível em: http://www.oecd.org/ els/emp/Skills-anticipation-flyer.pdf. Acesso em: 18 maio de 2020. 


\section{ENEM E OS PRINCÍPIOS EDUCACIONAIS NA ESFERA POLÍTICA: ELEMENTOS PARA A CRÍTICA}

Os resultados e as discussões amparadas pela Teoria Crítica da Sociedade nos levam a compreender que para atender às necessidades da sociedade industrial desenvolvida, a educação se põe como um meio para formar um novo perfil de trabalhador com habilidades e capacidades intelectuais que favorecem a sua adaptação à produção flexível.

Disseminou-se a ideia de que para sobreviver à concorrência, para conseguir ou manter um emprego, para ser cidadão do século XXI, seria preciso dominar os códigos da modernidade (SHIROMA; MORAES; EVANGELISTA, 2011).

Estes códigos devem estar em consonância com as técnicas para lidar com as novas tecnologias, mas também relacionados a comportamentos dos indivíduos que devem ter competências para a resolução de problemas, a tomada de decisões individuais, quer dizer, que participem ativamente no processo de reprodução da sociedade.

Não diferentemente, os documentos que norteiam as reformas curriculares nacionais trazem a ideia de competências e habilidades que capacitem essas pessoas na resolução de problemas.

Na coleta de dados que permitem identificar o perfil da formação do aluno do ensino médio, identificamos, nos três documentos que norteiam os fundamentos do Enem, o termo 'competências' que significa "modalidades estruturais da inteligência”. Este termo está ligado a ações que permitem efetivar relações com e entre objetos, situações, fenômenos e pessoas. Já as habilidades são as competências já adquiridas e estão ligadas ao plano imediato do saber-fazer. As habilidades podem ser aprimoradas e articuladas, promovendo nova reorganização das competências (BRASIL, 2000, 2001, 2002).

Neste sentido, a competência é de ordem geral, enquanto a habilidade é uma competência de ordem particular, específica. Assim, definidas as competências cognitivas globais, são determinadas as habilidades correspondentes a cada uma das competências, criando-se a matriz que permite indicações do que é valorizado na avaliação para, assim, orientar a formulação de questões em diferentes áreas do conhecimento.

As competências globais são formadas por cinco eixos principais: Dominar Linguagens (DL); Construir Argumentações (CA); Compreender Fenômenos (CF); Enfrentar situações-problema (SP) e Elaborar Propostas (EP) que podem ser resumidos nas seguintes ações: comunicar, conhecer e agir. As principais habilidades ligadas a essas competências são: identificar, reconhecer, comparar, relacionar, caracterizar, classificar, valorizar, ordenar e contextualizar (BRASIL, 2000, p. 10; 2001, p. 16; 2002, p. 12).

Todas essas ações confirmam os argumentos de Fonseca (2009) em relação à padronização de comportamentos aceitáveis: as ações de comunicar, conhecer e agir estão envolvidas com o saber-fazer imediato; não buscam a reflexão e a experiência formativa.

São propostas embasadas por teorias como a de Perrenoud (1999, 2000), Morin (2011) e Meireu (1998) que chegam a surpreender por suas intenções humanistas, mas são propostas que coadunam com a política educacional já descrita. Os autores defendem um ensino por meio de 'competências', entendidas como saberes necessários à educação do futuro, realizando críticas à formação que deve se configurar como resposta às exigências do mundo do trabalho quando, na verdade, objetivam moldar o perfil do indivíduo para se ajustar a um contexto produtivo de base flexível.

Um perfil múltiplo, cujos sujeitos consigam sobreviver e se adaptar no mundo do não emprego, da tecnologia, ou seja, para que saiba caminhar de acordo com o progresso e a regressão, o que demanda o desenvolvimento de 'novas competências'. Em direção aos desafios que a educação deve propor, estão as “situações-problema” de Meireu (1998), criador dessa expressão e motivador das reformas pedagógicas realizadas na França nos anos de 1990.

A estruturação do Enem por competências e habilidades permite a quem dele participe perceber o mundo ao seu redor por meio de situações-problema, sendo provocado a agir, mesmo que em pensamento (BRASIL, 2002). Mas, será que de fato permite o agir do participante? O que significa agir diante de situações-problema? É o agir reduzido ao imediato, ao saber-fazer, sem relacionar-se à reflexão, destituído do caráter formador. 
Trata-se do agir para resolver situações-problema na comunidade, em relação ao desemprego, aos problemas ambientais, sociais, educacionais, dentre outros, que não deixa de ser fundamental, contudo está voltada para uma ação adaptativa sem reflexão crítica, que faz enxergar tão somente os aspectos superficiais.

Mediante essas exposições, é possível dizer o porquê de o Enem avaliar 'competências': o Exame vai ao encontro de estratégias do ponto de vista da organização do sistema capitalista atual que, para se manter estável, precisa manter os sujeitos crentes que são autônomos e independentes para gerirem o seu próprio destino.

A 'competência' é a base para que o sujeito pós-moderno possa criar as 'estratégias' de sobrevivência na 'aldeia global'. São preocupações (i) com as formas de pensar voltadas ao controle, (ii) com as formas de compreender e de interpretar, ou ainda, (iii) o controle do discurso. Em suma, uma avaliação para o treinamento de habilidades, bem como do pensamento conformista.

No material ENEM - fundamentação teórico-metodológica, MACEDO (2005, p. 17) explica a importância do uso atual dos termos ‘competências' e 'habilidades' e apresenta algumas razões que permitem a reflexão pedagógica. Para falar desses termos, ele pontua que, até bem pouco tempo, o ensino centrava-se em conceitos e isso estava atrelado ao conhecimento.

O autor prossegue dizendo que, ao dar aula, o professor exercia um papel intelectual interessante, mas que nem todos os estudantes conseguiam aprender e muito menos eram estimulados a pensar. Contudo, com as mudanças tecnológicas, sociais e culturais, essa visão tende a mudar.

Por isso, esse "tipo de aula” não perde seu espaço, mas “é necessário também o domínio de um conteúdo chamado de 'procedimental', ou seja, da ordem do 'saber como fazer'”. A questão é saber o que fazer com as informações já processadas pelos computadores, saber interpretar "na busca da solução de nossos problemas ou daquilo que temos vontade de saber” (MACEDO, 2005, p. 17).

Pela perspectiva das ‘competências', o “aprender a aprender” (BRASIL, 2002, p. 28) precisa ser desenvolvido pelas diversas situações às quais os sujeitos são submetidos, tais como a escrita de um texto no computador, em que o processador de textos pode ajudar em diversas situações, todavia antes que eles conheçam todas as funções dos programas disponíveis, uma nova versão é criada. Por isso, o sujeito precisará “descobrir” essa nova versão e seus recursos também modificados.

Assim, a avaliação apresenta, por meio das 'competências', estratégias para a eficiência. O estudante avaliado deve ser capaz de reconhecer, selecionar, organizar, relacionar informações e interpretar dados disponíveis em um texto, ou seja, um indivíduo que seja capaz de agir, aquele que usa a dimensão procedimental da competência. São capacidades previstas por Perrenoud (1999), sendo o que se espera na avaliação: a tomada de decisão diante de situações-problema.

Este aspecto da avaliação remete à discussão de Horkheimer (2002, p. 9) no texto Meios e fins, no qual ele explica que a razão para o "homem médio" está ligada à utilidade e o que torna possível as forças racionais é a "faculdade de classificação, inferência e dedução, não importando o conteúdo específico dessas ações: ou seja, o funcionamento abstrato do mecanismo de pensamento". Portanto, trata-se da razão subjetiva que se relaciona com os fins.

De acordo com Horkheimer (2002, p. 15), o princípio de ajustamento à realidade é dado como certo. Para melhor apresentar o seu argumento, traz como exemplo a maneira pela qual o juiz indaga o acusado num tribunal de trânsito. O juiz ao perguntar: "Fez tudo que estava ao seu alcance para proteger a própria vida e propriedade suas e as de outras pessoas, e para obedecer a lei?”, ou seja, o questionamento se restringe aos valores que devem ser respeitados, à adequação do comportamento aos padrões reconhecidos, na superficialidade dos fatos.

O avaliado precisa ser capaz de resolver situações-problema interdisciplinares das ciências, das artes e da filosofia e tem a ver com o mundo em que vive. Deve saber ler todas as formas de linguagens possíveis, tais como: dados, gráficos, figuras, textos, charges, algoritmos, desenhos, entre outras. As situações-problema devem levar o participante a um "conflito cognitivo" para que ele possa agir utilizando conhecimentos construídos anteriormente, reorganizando-os para encarar o desafio da situação proposta pela literatura (BRASIL, 2000, 2001). 
Todas as ações de saber ler todas as formas de linguagens são importantes, contudo, quando o que está em primeiro plano é resolver situações-problema, ou ainda, agir mediante uma "provocação" conforme propostas feitas por Perrenoud (1999, 2000), Morin (2011) e Meireu (1998), basta ao avaliado identificar, selecionar e reconhecer. Não se trata, portanto, de avaliar o conhecimento apropriado ao longo da educação do jovem ou o adulto que participa do Exame.

É uma concepção de formação que critica o conhecimento quando este se torna enciclopédico: o importante é resolver situações-problema relacionadas à sua realidade, o foco está no reconhecimento das formas, nas técnicas presentes para a formulação dos vários textos, em seus objetivos para o uso social.

O conhecimento dos clássicos, elementares para a constituição do indivíduo, já que traziam o conteúdo universal, se desfaz; é considerado inútil. É certo que o uso social do conhecimento tem sua importância; todavia nossa defesa é pelo conhecimento como base, como sustentação e não o contrário, a partir da identificação, da decifração, do reconhecimento, e da seleção, revelando que nossa formação não é para a resistência.

Falar em resistência é refletir no quanto “não somos educados para a emancipação”, é compreender o direito que vem disfarçado de oportunidade, é pensar, como cita Adorno (1995, p. 170), a "estruturação tríplice”, ou seja, uma escola para os que são bem dotados, outra para os medianos e outra para os “desprovidos de talento".

Assim, podemos pensar as propostas educativas contrárias à resistência e à reflexão que pendem para o lado subjetivo, como as encontradas em documentos internacionais que delineiam as políticas educacionais em nosso país, nos próprios documentos do Enem e em autores que coadunam e reforçam propostas minimalistas para a educação, como Perrenoud (1999, p. 7) que define competência como "uma capacidade de agir eficazmente em um determinado tipo de situação, apoiada em conhecimentos, mas sem limitar-se a eles” e Morin (2011), para quem os saberes necessários à educação do futuro estão ligados às competências defendidas por Perrenoud.

São propostas que têm orientado a formação que se almeja; logo, o que deve ser avaliado também. Essa forma de pensar a educação ratifica a racionalidade tecnológica sobre a qual Marcuse (1999, p. 84) escreve e põe em destaque os padrões de comportamentos que transformam a "[...] força crítica em uma força de ajuste e submissão".

Mediante a Teoria Crítica da Sociedade ${ }^{13}$ compreendemos que o Enem segue a ideologia da formação para as competências, ou seja, está voltado a uma sociedade que define formas de organização e pensamentos para o desempenho eficiente ou, ainda, para o "controle efetivo, [e a] conduta correta" (MARCUSE, 1999, p. 84).

Os autores frankfurtianos defendem uma educação que suscite a crítica à ideologia vigente; uma educação capaz de formar indivíduos autônomos e emancipados. Assim, pode mostrar os limites de modo que esse indivíduo se fortaleça, deixando transparecer as formas que impossibilitam a formação humana.

Nesse sentido, aponta-se a necessidade de desvelarmos a ideia de formação que está na base das avaliações nacionais. Nessa perspectiva, a educação transformada em mercadoria utiliza-se de instrumentos para levar professores, alunos e pais a competirem por um "lugar ao sol” de acordo com Crochík (2009, p. 16) ou "à base de cotoveladas" conforme Adorno (1995, p. 162), ou seja, competirem por uma vaga no ensino superior por meio do Enem.

Para Adorno (1995, p. 162) a competitividade é um instrumento utilizado pela educação a fim de aumentar a eficiência. Nesse sentido, entendemos o Enem como um instrumento que promete um "lugar ao sol”. Contrário a esta formação competitiva e sem reflexão, Adorno revela a necessidade de que a contradição social esteja posta; portanto, é fundamental que a educação seja política de acordo com Crochík (2009, p. 23).

\footnotetext{
${ }^{13}$ A Teoria Crítica é um pensamento filosófico criado pela Escola de Frankfurt, fundada em 1924 por “iniciativa de Félix Weil, filho de um grande negociante de grãos de trigo na Argentina”, que se propõe a estudar o movimento das mudanças sociais. É uma Escola que buscava a crítica, pois seus pensadores exprimiam a decepção de grande parte dos intelectuais em relação às modificações do mundo contemporâneo. Para além da crítica, também procuravam completar um espaço acerca do movimento revolucionário e de sua teoria - o marxismo -, em especial ao que pertence “à teoria e à prática do movimento operário alemão depois da Primeira Guerra Mundial e do desmoronamento do regime imperial” (MATOS, 2009, p. 7-8).
} 
Compreendemos que a possibilidade do conhecimento não está em tão somente ser mera transmissão de conteúdos, mas a busca pela produção de uma consciência verdadeira (ADORNO, 1995, p. 141). A possibilidade está relacionada com o deixar em evidência, em primeiro momento, o que destituiu o conhecimento de seus princípios emancipadores.

Observa-se pela análise do Enem e a formação requerida pelos documentos nacionais neste trabalho estudados, os internacionais, bem como os dados indicadores da OECD, que tudo segue a forma da razão instrumentalizada.

O processo do pensamento é alterado para o modo automático, não pelo conhecimento, mas pelo mecanicismo, que coloca de lado o pensar sobre o pensamento, que se converte em coisa, em instrumento em prol do procedimento. Para fazer uma análise crítica, o caminho é identificar as fendas deixadas e buscar na autorreflexão crítica a possibilidade de emancipação.

\section{CONSIDERAÇÕES FINAIS}

Voltarmos o olhar para as competências e habilidades exigidas do avaliado no Enem é uma das formas de criticar, de revelar que se trata de uma ideia de desenvolver estratégias que leve o indivíduo a ser eficiente para saber agir diante de uma situação-problema que parte de uma realidade familiar, isto é, uma forma que não admite uma certa distância diante da realidade empírica e que, portanto, não permite a reflexão.

As reformas e as políticas educacionais foram reduzidas à avaliação em larga escala, evidenciando que, na sua função, a educação escolar foi reduzida ao atendimento da lógica do capital, conforme explica Fonseca (2009, p. 154): “[...] do ângulo puramente pragmático, a educação de qualidade se resume ao provimento de padrões aceitáveis de aprendizagem para inserir o indivíduo - como produtor-consumidor - na dinâmica do mercado".

Além de ser considerado como mercado promissor, o Enem, por meio de seus relatórios, promove reflexões sobre a didática, o currículo educacional vigente e também possibilita, na visão do Inep (BRASIL, s/d.a), melhorar as políticas de educação para o ensino médio.

Assim, o Exame é expressão de marcos ideológicos de cada governo, por isso está na condição de política educacional: como sua forma não é permanente, por meio dessa avaliação é possível alterar o conteúdo da educação de modo a sustentar o que hoje significa primar por competências e habilidades, modificações e adaptações que estejam de acordo com o esperado para o contexto econômico-social.

O Enem, como expressão da política educacional que sustenta as mudanças políticas de cada governo, segue uma matriz de competências e habilidades que vai ao encontro de documentos como os da OECD, do BM e da UNESCO. Portanto, o pensamento pela reflexão deve colocar em evidência que a conivência com a formação pelas competências é parte da exploração.

A investigação que aqui conduzimos aponta que o encaminhamento dado à educação, ao mudar da objetividade e da subjetividade para a autoresponsabilidade, para a cidadania, para o autoconhecimento, para a resolução de problemas e o convívio com o outro, significa a forma de garantir a permanência da sociedade da exploração.

Nesse sentido, para a "sociedade da informação" ou do "conhecimento", o ensino precisa ser flexível; o sujeito precisa ser "aprendente” para haver, como afirmam Shiroma, Moraes e Evangelista (2011, p. 12), um menor desperdício de recursos humanos.

Vale ressaltar que as avaliações nacionais e as reformas curriculares são grandes instrumentos atrelados um ao outro; um para determinar a educação que se espera; o outro para medir se o que se espera está acontecendo. Da mesma forma, a avaliação exerce forte pressão sobre as reformas curriculares de modo a calibrar a formação de acordo com o que a sociedade necessita.

Com a reflexão realizada, percebemos o quanto as pequenas partes de um sistema têm muito a nos dizer quando o vasculhamos para descortinar a verdadeira razão de sua existência. O Enem é uma dessas pequenas partes que revela uma formação em que é definido o comportamento dos sujeitos para atender 
à organização da sociedade e ao modo como o trabalho se realiza, ou não se realiza porque já não é mais necessário para produzir, todavia o sujeito não é dele dispensado para sobreviver.

O Enem é expressão da sociedade, por isso a forma como é estruturado responde às demandas de políticas internacionais que definem o caminho para as competências, sendo a partir dessa leitura possível entender a que projeto social uma avaliação de larga escala atende.

O conhecimento é fundamental para a produtividade econômica e, para isso, o indivíduo deve conhecer os códigos da modernidade que incluem ter um novo perfil com habilidades e capacidades coerentes com a produção flexível. As capacidades do indivíduo estão em ser empreendedor, ser criativo, ser hiperconectado, saber comunicar-se, influenciar e negociar. O desempenho eficiente é o destino final para a educação, quando o discurso da formação para o trabalho é mera ideologia.

Enfim, o desafio que se faz necessário para o século XXI é criticar a ideologia vigente nas "disposições psíquicas que procura mobilizar nos indivíduos” (CROCHÍK, 2009, p. 23). É nesse sentido que a educação deve ser para a contradição e para a resistência, por meio de possibilidades históricas emancipatórias. Embora a educação não possa ser redentora, ela significa e possibilita a necessidade de crítica permanente, permitindo a autoreflexão crítica.

De acordo com Marcuse (1973, p. 14), a formação para a conscientização está em investigar as origens dos fatos e as alternativas históricas para a emancipação humana. A defesa pela crítica da ideologia vigente é parte essencial da Teoria Crítica da Sociedade, a denúncia de uma pseudoformação coloca a educação como possibilidade para a reflexão.

Os resultados e as discussões da pesquisa revelam que ter competências se põe acima do conhecimento, já que avaliar se determinados conteúdos foram apropriados pelo participante fica em segundo plano. Para tanto, são engrandecidas ações que devem ser avaliadas no aluno, tais como: identificar, reconhecer, comparar, relacionar, caracterizar, classificar, valorizar, ordenar e contextualizar.

Com a ideia e com o compromisso traçados por instâncias superiores, a educação escolar e tudo aquilo que a envolve - inclusive as avaliações em larga escala - direcionam a formação às capacidades já destacadas, as quais dão a impressão de que se está objetivando o desenvolvimento de indivíduos cujo pensamento seja capaz de analisar criticamente a realidade, sem positivizá-la. Isso nos remete a padronização do pensamento do indivíduo (MARCUSE, 1999).

Nesse sentido, analisar uma avaliação em larga escala é uma das formas pelas quais podemos chegar a elementos considerados fundamentais para a formação de sujeitos com competência para atuar no mundo atual. Conforme Marcuse (1973, p. 55), citando Platão e Rousseau, vivemos em uma "ditadura educacional”, já que somos condicionados a agir para nos adaptarmos à realidade e não formados para analisá-la criticamente; somos constantemente levados a acreditar que somos livres, embora nossa vida seja regida pela funcionalidade. Mas está na crítica permanente à possibilidade de reflexão, a possibilidade de contradição e de emancipação.

\section{REFERÊNCIAS}

ADORNO, T. Educação e emancipação. 2. ed. Paz e Terra, 1995.

BANCO MUNDIAL. Aprendizagem para todos. Estratégia 2020 para a Educação do Grupo Banco Mundial. Resumo Executivo. Washington, 2011. Disponível em: http://siteresources.worldbank. org/EDUCATION/Resources/ESSU/463292-1306181142935/Portguese_Exec_Summary_ESS2020_ FINAL.pdf. Acesso em 27 fev. 2020.

BANCO MUNDIAL. Brazil - secondary education in Brazil: Time to move forward, 2000. Disponível em: http://documents.worldbank.org/curated/pt/825211468020042139/pdf/multi-page.pdf. Acesso em 27 fev. 2020.

BAUMAN. Z. Modernidade líquida. Rio de Janeiro: Jorge Zahar, 2001. 
BRASIL. Ministério da Educação. Instituto Nacional de Estudos e Pesquisas Educacionais Anísio Teixeira - INEP. Enem - Apresentação. s/d.a. Disponível em http://portal.mec.gov.br/enem-sp-2094708791. Acesso em 27 fev. 2020.

BRASIL. Ministério da Educação. Instituto Nacional de Estudos e Pesquisas Educacionais Anísio Teixeira - INEP. Exame Nacional do Ensino Médio. Documento básico. Brasília, 2000. Disponível em http://portal.inep.gov.br/documents/186968/484421/Exame+Nacional+do+Ensino+M\%C3\%A9dio++ENEM++documento+b\%C3\%A1sico/e2cf61a8-fd80-45b8-a36f-af6940e56113?version=1.1. Acesso em 27 fev. 2020.

BRASIL. Ministério da Educação. Instituto Nacional de Estudos e Pesquisas Educacionais Anísio Teixeira - INEP. Exame Nacional do Ensino Médio. Documento básico. Brasília, 2001. Disponível em http://smeduquedecaxias.rj.gov.br/nead/Biblioteca/Forma\%C3\%A7\%C3\%A3o\%20Continuada/ Avalia\%C3\%A7\%C3\%A3o/enem/ENEM\%202001.pdf. Acesso em 27 fev. 2020.

BRASIL. Ministério da Educação. Instituto Nacional de Estudos e Pesquisas Educacionais Anísio Teixeira - INEP. Exame Nacional do Ensino Médio. Documento básico. Brasília, 2002, 27 p. Disponível em http://portal.inep.gov.br/documents/186968/484421/ENEM+-+Exame+Nacional+do+Ensino+M\%C3 \%A9dio+documento+b\%C3\%A1sico+2002/193b6522-cd52-4ed2-a30f-24c582ae941d?version=1.2. Acesso em 27 fev. 2020.

BRASIL, Ministério da Educação. Instituto Nacional de Estudos e Pesquisas Educacionais Anísio Teixeira. INEP. Exame nacional do ensino médio (Enem): Fundamentação teórico-metodológica. Brasília: O Instituto, 2005. Disponível em http://portal.inep.gov.br/documents/186968/484421/ ENEM+-+Exame+Nacional+do+Ensino+M\%C3\%A9dio+fundamenta\%C3\%A7\%C3\%A3o+te\%C3 \%B3rico-metodol\%C3\%B3gica/449eea9e-d904-4a99-9f98-da804f3c91f5?version=1.1. Acesso em 27 fev. 2020.

BRASIL, Ministério da Educação. Instituto Nacional de Estudos e Pesquisas Educacionais Anísio Teixeira. Relatório final Enem 1998. Brasília: INEP, 1998b. Disponível em: http://portal.inep.gov.br/ documents/186968/484421/ENEM+-+Exame+Nacional+do+Ensino+M\%C3\%A9dio+relat\%C3\%B3ri o+final+98/f4cf226a-6961-4289-9afb-da8c0032ff89?version=1.2. Acesso em: 18 de maio 2020.

BROOKE, N. O futuro das políticas de responsabilização educacional no Brasil. Cadernos de Pesquisa, v. 36, n. 128, p. 377-401, maio/ago. 2006. Disponível em: http://www.scielo.br/pdf/cp/ v36n128/v36n128a06.pdf. Acesso em 28 fev. 2020.

CAFIERO, D. Leitura como processo: caderno do professor: Belo Horizonte: Ceale/FaE/UFMG, 2005.

CHAUÍ, M. Cultura e democracia: o discurso competente e outras falas. São Paulo: Cortez, 1983.

CROCHÍK, J. L. Educação para a resistência contra a barbárie. Revista Educação, Coleção Especial: Biblioteca do Professor, Adorno pensa a Educação. São Paulo: Editora Segmento, ano 2, n. 10, p.16-25, 2009.

DELORS, J. (Org). Educação: um tesouro a descobrir. Relatório para a UNESCO da Comissão Internacional sobre educação para o século XXI. São Paulo: Cortez, 1996. Disponível em: http://dhnet. org.br/dados/relatorios/a_pdf/r_unesco_educ_tesouro_descobrir.pdf. Acesso em: 18 de maio 2020

FONSECA, M. Políticas públicas para a qualidade da educação brasileira: entre o utilitarismo econômico e a responsabilidade social. Caderno Cedes, Campinas Vol. 29, n. 78, p. 153-177, maio/ago. 2009.

FORRESTER, V. O horror econômico. São Paulo: UNESP, 1997.

HORKHEIMER, M. Eclipse da razão. São Paulo: Centauro, 2002.

MACEDO, L. Competências e habilidades: Elementos para uma reflexão pedagógica. In: Ministério da Educação/Instituto Nacional de Estudos e Pesquisas Educacionais Anísio Teixeira. Exame Nacional do Ensino Médio (Enem): fundamentação teórico-metodológica. Brasília: MEC/INEP, 2005. p. 13-28.

MARCUSE, H. A Ideologia da sociedade industrial. O homem unidimensional. Rio de Janeiro. 1973. Zahar editores. 
MARCUSE, H. Algumas implicações sociais da tecnologia moderna In Tecnologia, guerra e fascismo. São Paulo: Editora da Unesp, 1999. p. 73-104.

MATOS, O. C. F. T. W. Adorno: notas biográficas. Revista Educação: biblioteca do professor, ano 2, n. 10, p. 6-155, 2009.

MEIREU, P. Aprender... sim, mas como? Tradução Vanise Dresch. 7. ed. Porto Alegre: Artes Médicas, 1998.

MORIN, E. Os sete saberes necessários à educação do futuro. Tradução de Catarina Eleonora F. da Silva de Jeanne Sawaya; revisão técnica de Edgard de Assis Carvalho. 2. ed. rev. São Paulo: Cortez; Brasília, DF: UNESCO, 2011.

OECD. Organization for economic co-operation and development. Better life index. s/d. a. Disponível em: http://www.oecdbetterlifeindex.org/countries/brazil/. Acesso em: 27 fev. 2020.

OECD. Organization for economic co-operation and development. Better policies for better lives. s/d. b. Disponível em: http://www.oecd.org/skills/. Acesso em: 27 fev. 2020.

OECD. Organization for economic co-operation and development. Better policies for better lives. World Indicators of Skills for Employment (WISE) database. s/d. c. Disponível em: http://www.oecd.org/ employment/skills-for-employment-indicators.htm. Acesso em: 18 de maio de 2020.

OECD. Organization for economic co-operation and development. Education: The OECD's work on education helps individuals and nations to identify and develop the knowledge and skills that drive better jobs and better lives, generate prosperity and promote social inclusion. s/d. d. Disponível em: http://www.oecd.org/education/. Acesso em: 27 fev. 2020.

OECD. Organization for economic co-operation and development. Getting Skills Right: Assessing and responding to changing skill needs. s/d. e. Disponível em: http://www.oecd.org/els/emp/Skillsanticipation-flyer.pdf. Acesso em: 18 maio de 2020.

OECD. Organization for economic co-operation and development. Stat. 2015. Disponível em: https:// stats.oecd.org/Index.aspx?_ga=2.194134637.1989541583.1545649244-474786757.1465906249. Acesso em: 18 de maio de 2020.

PERRENOUD, P. Construir as competências desde a escola. Porto Alegre: Artes Médicas, 1999.

PERRENOUD, P. 10 novas competências para ensinar: convite à viagem. Porto Alegre: Artes Médicas Sul, 2000.

ROPÉ, F.; TANGUY, L. (Org). Saberes e competências: O uso de tais noções na escola e na empresa. Campinas, SP: Papirus, 1997.

SHIROMA, E. O.; MORAES, M. C. M.; EVANGELISTA, O. Política educacional. Rio de Janeiro: Lamparina, 4. ed., 2011. 